\title{
Transanal Tube Drainage as a Conservative Treatment for Anastomotic Leakage Following a Rectal Resection
}

\author{
Mostafa Shalaby ${ }^{1,2}$, Waleed Thabet ${ }^{2}$, Oreste Buonomo ${ }^{1}$, Nicola Di Lorenzo ${ }^{1}$, Mosaad Morshed ${ }^{2}$, \\ Giuseppe Petrella ${ }^{1}$, Mohamed Farid ${ }^{2}$, Pierpaolo Sileri ${ }^{1}$ \\ ${ }^{1}$ Department of General Surgery, Policlinico Tor Vergata Hospital, University of Rome Tor Vergata, Rome, Italy; ${ }^{2}$ Department General Surgery, \\ Mansoura University Hospitals, Mansoura University, Mansoura, Egypt
}

Purpose: We evaluate the role of transanal tube drainage (TD) as a conservative treatment for patients with anastomotic leakage (AL).

Methods: Patients treated for AL who had undergone a low or an ultralow anterior resection with colorectal or coloanal anastomosis for the treatment of rectal cancer between January 2013 and January 2017 were enrolled in this study. The data were collected prospectively and analyzed retrospectively. The primary outcomes were the diagnosis and the management of AL.

Results: Two hundred thirteen consecutive patients, 122 males and 91 females, were included. The mean age was $66.91 \pm$ 11.15 years, and the median body mass index was $24 \mathrm{~kg} / \mathrm{m}^{2}$ (range, $\left.20-35 \mathrm{~kg} / \mathrm{m}^{2}\right)$. The median tumor distance from the anal verge was $8 \mathrm{~cm}$ (range, 4-12 cm). Ninety-three patients (44\%) received neoadjuvant therapy for nodal disease and/or locally advanced rectal cancer. Only 13 patients (6\%) developed AL. Six patients developed subclinical AL as they had a defunctioning ileostomy at the time of the initial procedure. They were treated conservatively with TD under endoscopic guidance in the endoscopy unit and received intravenous antibiotics. Six weeks after discharge, these 6 patients underwent follow-up flexible sigmoidoscopy which showed a completely healed anastomotic defect with no residual stenosis. Seven patients developed a clinically significant $\mathrm{AL}$ and required reoperation with pelvic abscess drainage and Hartmann colostomy formation.

Conclusion: These results suggest that TD for management of patients with AL is safe, cheap, and effective. Salvaging the anastomosis will help decrease the need for Hartmann colostomy formation. Proper patient selection is important.

\section{Keywords: Anastomosis; Anastomotic leakage; Rectal cancer; Transanal tube drainage}

\section{INTRODUCTION}

Anastomotic leakage $(\mathrm{AL})$ is considered the most devastating complication after surgery for rectal cancer. It is associated with increased morbidity, length of hospital stay, and rate of reinter-

Received: July 20,2017 - Accepted: October 18, 2017

Correspondence to: Mostafa Shalaby, M.D.

Department General Surgery "8", Mansoura University Hospitals, Mansoura University, 60 ElGomhouria Street, 35516, Mansoura, Dakahliya, Egypt

Tel: +201020555705, Fax: +20502228000

E-mail: mostafashalaby@mans.edu.eg

ORCID code: https://orcid.org/0000-0002-0358-2398

(C) 2018 The Korean Society of Coloproctology

This is an open-access article distributed under the terms of the Creative Commons Attribution NonCommercial License (http://creativecommons.org/licenses/by-nc/4.0) which permits unrestricted noncommercial use, distribution, and reproduction in any medium, provided the original work is properly cited. vention, as well as poor oncological outcome. Furthermore, the consequences of AL may extend to life-threatening complications with increased mortality [1]. Because the literature lacks evidencebased strategies for managing AL, Phitayakorn et al. [2], in an expert consensus of 43 colorectal surgeons and interventional radiologists, drew an algorithm for the management of patients with AL. That algorithm depended on whether the leakage was intraperitoneal vs. extraperitoneal or subclinical vs. clinical and on whether the anastomosis was diverted or nondiverted. Moreover, individualization of the treatment is important, and factors such as the general condition of the patient, the size of the anastomotic defect, the indication of the primary resection, the presence of a defunctioning stoma, the anastomotic level, and the interval between initial surgery and diagnosis should be considered [3]. However, in every case, the treatment should be started as soon as 
the diagnosis is confirmed [4].

Soeters et al. [5], in their review of patients with a colorectal AL, highlighted that the extent of anastomotic dehiscence, the abscess size, the presence of fecal peritonitis, and the patient's general conditions were important determinants of the management strategy. They recommended that the anastomosis should be resected with the creation of Hartmann colostomy when dehiscence of more than half of the circumference, extensive abscess, or fecal peritonitis is present or when the patients are high risk. Surgeons advocate that the Hartmann colostomy will remove the source of sepsis, especially for an intraperitoneal anastomosis, reserving the strategy of "divert and drain" for an extraperitoneal anastomosis with loop ileostomy and pelvic drainage salvaging of the anastomosis [6].

Krarup et al. [7] found that proximal diversion in a patient with an intraperitoneal AL has a threefold success probability for stoma reversal compared to Hartmann procedure. However, caution should be exercised because as many as $23 \%$ of such diversions as a result of leakage will be permanent [8]. Lindgren et al. [9] stated that more than $50 \%$ of the patients who were offered a Hartmann procedure were left with a permanent stoma. Edden and Weiss [10] identified a limited and shortened surgical intervention combined with adequate abdominal lavage and proximal diversion as important principles that should be applied no matter the method used for additional intervention. Reoperation is rarely indicated in patients with a defunctioning stoma at the time of initial operation, which is usually the case for an extraperitoneal anastomosis, and nonsurgical treatments include transanal anastomotic tube drainage or percutaneous drainage of the pelvic collection guided by ultrasonography (US) or computed tomography (CT), as well as newer technologies such as endoscopic endoluminal vacuum-assisted therapy, endoscopic stenting, or clip placement [6].

The use of a transanal/transrectal tube to drain the abscess cavity for the treatment of a patient with a colorectal AL was first described by Thorson and Thompson [11], who aimed mainly to preserve the anastomosis. They employed a 16F Foley catheter transrectally for AL following a low anterior resection (LAR) and utilized standard rigid proctosigmoidoscopy under direct inspection. The catheter was put in place by inflating a balloon and was additionally secured to the buttocks by using tape. They used the catheter to irrigate the cavity with physiological saline four times a day in order to drain the abscess cavity and relieve the sepsis; this was combined with a low residue diet. After removal of the catheter, the patients returned to normal diet, and bowel continuity was maintained. They advocated criteria for selecting patients; those included posterior leakage diagnosed radiologically, fever and leukocytosis, and the absence of any other pathology. The beneficial effects of TD could be attributed to direct drainage, which decreased the intraluminal pressure and promoted motility [12].

\section{METHODS}

Patient who had undergone a curative open or laparoscopic LAR or an ultralow anterior resection (ULAR) with a colorectal or coloanal anastomosis for rectal cancer between January 2013 and January 2017 were considered for inclusion in this study. Patients who were pregnant, had recurrent disease, had a tumor located more than $12 \mathrm{~cm}$ from the anal verge, had undergone an abdominoperineal resection, had a colorectal or coloanal anastomosis after Hartmann procedure, had undergone emergency surgery, or had intraoperative evidence of leakage were excluded. The data were collected prospectively and analyzed retrospectively. All patients provided written informed consent, which included the possibility of future publication. Institutional Review Board approval was obtained from the local Ethical Committee of the Rome Tor Vergata University Hospital in compliance with the Principles of the Helsinki Declaration.

All cases were discussed at colorectal multidisciplinary meetings, and all patients underwent preoperative staging, which included colonoscopy with biopsy, chest CT, abdomen and pelvis CT, identification of tumor markers (carcinoembryonic antigen, carbohydrate antigen 19-9), and/or endorectal US. The level of the tumor was measured from the lower border of the tumor to the anal verge by using flexible sigmoidoscopy and was considered low for a level $<6 \mathrm{~cm}$, middle for a level of 6-12 cm, or upper for a level $>12 \mathrm{~cm}$. All patients were also seen in the preassessment clinic and were carefully evaluated by consultant anesthetists. Neoadjuvant therapy was offered in the form of long-course chemoradiotherapy to patients with a nodal disease or locally advanced resectable rectal cancers, and the surgery was scheduled 8 to 12 weeks after completion of therapy. Adjuvant chemotherapy was routinely recommended, while postoperative radiotherapy was only indicated in case of positive resection margins.

The day before surgery, all patient received mechanical bowel preparation with polyethylene glycol, along with an additional liquid diet. An adequate thromboembolic prophylaxis with low molecular weight heparin was given the evening before the surgery. Antibiotic prophylaxis with second-generation cephalosporin $(1 \mathrm{~g})$ and metronidazole $(500 \mathrm{mg})$ was administered at induction of anesthesia.

Laparoscopic surgery was performed using the 4-trocar technique with a $30^{\circ}$ scope with medial-to-lateral dissection. In both open and laparoscopic surgeries, we performed high ligation of the inferior mesenteric artery, followed routinely by full mobilization of the splenic flexure. A total mesorectal excision was performed in the standardized way as described by Heald [13] with the anastomoses being performed by using the double stapling technique. A defunctioning ileostomy was constructed when technical difficulties were encountered while performing the anastomosis. For this study, we adopted the definition of AL published by the International Study Group of Rectal Cancer (ISGRC) [14]: “...Defect of the intestinal wall integrity at the colorectal or 
coloanal anastomotic site (including suture and staple lines of neorectal reservoirs) leading to a communication between the intraand extraluminal compartments. A pelvic abscess close to the anastomosis is also considered as anastomotic leakage."

For the end-point of the study, patients were followed-up on the ward and then in the outpatient department at 2 weeks and 1 month postoperative. Patients who were suspected of having $\mathrm{AL}$ underwent $\mathrm{CT}$ with rectal contrast to assess the integrity of the anastomosis. The primary outcome was the diagnosis and the management of the AL during 30 days postoperative. Data were analyzed using excel and IBM SPSS Statistics ver. 21.0 (IBM Co., Armonk, NY, USA). Quantitative data were expressed as means and standard deviations or as medians and ranges according to normality.

\section{RESULTS}

Two hundred thirteen consecutive patients, 122 males and 91 females, with primary rectal cancer were included in the study. The mean age was $66.91 \pm 11.15$ years, and the median body mass index was $24 \mathrm{~kg} / \mathrm{m}^{2}$ (range, $20-35 \mathrm{~kg} / \mathrm{m}^{2}$ ). The median tumor distance from the anal verge was $8 \mathrm{~cm}$ (range, $4-12 \mathrm{~cm}$ ). Ninetythree patients (44\%) received neoadjuvant therapy for nodal disease and/or locally advanced rectal cancer. One hundred fiftyfour patients underwent open surgery while 59 patients underwent laparoscopic surgery. Two hundred one patients underwent LAR with stapled colorectal anastomoses while the remaining 12 patients underwent ULAR with hand-sewn coloanal anastomoses. A defunctioning ileostomy was created in 87 patients at the time of initial surgery. Only 13 patients (6\%) developed AL. Six of those 13 patients developed a subclinical AL as they had a defunctioning ileostomy at the time of the initial procedure; the diagnosis, which was grade B according to the ISGRC [14], was made by using CT with rectal contrast. Those 6 patients were treated conservatively with both transanal anastomotic drainage under endoscopic guidance and intravenous antibiotics.

For the 6 patients who had developed a subclinical AL, transanal drainage (TD) was done in the endoscopy unit without the need for any type of anesthesia. The abscess cavity was identified and irrigated. Then, a 16F Foley catheter was placed adjacent to the cavity with its balloon inflated with $5 \mathrm{~mL}$ of physiological saline to secure it; additionally, the catheter was secured to the buttocks with silk suture. The catheter was connected to a urine bag to allow the amount and the color of the drainage to be monitored; daily irrigation with physiological saline was also done. The drain was removed when the patient became afebrile or the output ceased. Six weeks after discharge, all of these patients underwent follow-up flexible sigmoidoscopy, which showed a completely healed anastomotic defect with no residual stenosis. The seven patients who had developed a clinically significant AL, which presented as peritonitis, were grade $\mathrm{C}$ according to the ISGRC [14] grading system and required reoperation during which the pelvic abscess was drained, the previous anastomosis was resected, and Hartmann colostomy was performed.

\section{DISCUSSION}

Only 13 patients (6\%) developed AL in our study. This result agrees with the results in articles published by the MRC CLASSIC trial [15], Park et al. [16], and Kim et al. [17]. However, other articles reporting $\mathrm{AL}$ rates ranging from $0.4 \%$ to $17 \%$ were published by van der Pas et al. [18] in the COLOR II trial, Morino et al. [19], and Miyajima et al. [20]. This wide range of the AL rate may be attributed to the lack of both a consistent definition of AL and proper criteria for diagnosis. A prompt decision for patients with AL improves the outcome. Unfortunately, consensus on a perfect diagnostic modality for AL is lacking. Furthermore, radiological modalities have variable sensitivities and specificities and may delay definitive intervention [21].

When clinical findings are present, CT with rectal contrast is recommended because in comparison to conventional modalities, it has the diagnostic advantage of offering more accurate images of the anastomotic and the peri-anastomotic structures. Furthermore, it has a therapeutic value for percutaneous drainage of a localized abscess [22]. Currently, CT with contrast enema and water-soluble contrast enema are the most frequently applied studies in the detection of colorectal AL [2]. Kornmann et al. [22] in a systematic review of the value of CT in the detection of AL following colorectal surgery found that the diagnostic criteria were varied or undefined and that the overall sensitivity was $0.68(95 \%$ confidence interval $[\mathrm{CI}], 0.59-0.75)$. However, the specificities were calculated from only 2 studies and were 1.00 (95\% CI, 0.89 $1.00)$ and 0.78 (95\% CI, 0.57-0.91), respectively. False-negative CT scanning was reported in $24.4 \%$ of the patients in one study and caused a delay of over 24 hours. Separately, 3 studies of only rectal resections with administration of rectal contrast were analyzed; the sensitivity was 0.92 (95\% CI, $0.80-0.97)$, and 47 of the CT findings were true positive and 4 were false negative.

Six of our patients who developed subclinical AL were treated conservatively with TD and intravenous antibiotics. We employed TD to treat patients who were devoid of signs of peritonitis; this was the treatment of choice in those patients who had a defunctioning ileostomy at the time of initial operation. Six weeks after discharge, all 6 of these patients underwent follow-up flexible sigmoidoscopy, which showed a completely healed anastomotic defect with no residual stenosis. The beneficial effects of TD could be attributed to direct drainage, decreased intraluminal pressure and promotion of motility [12]. The remaining seven patients who developed clinically significant AL were not candidates for TD or conservative treatment, so additional reintervention was required to drain the pelvic abscess with the formation of Hartmann's colostomy.

Alternatively, a suction drain and chest tubes were used by Sirois-Giguère et al. [23] who published the largest series on the 
use of TD. They found TD to be a safe and effective way to treat patients with AL with a higher rate of stoma reversal for those patients with transanal tube drainage compared to those without, but this finding did not reach statistical significance. Another novel technique for TD is the use of a Heald Silastic Anal Stent (HSAS), which was originally proposed as an alternative to a defunctioning ileostomy to protect low colorectal anastomosis. Brent et al. [24] reported that a HSAS efficiently decompressed the rectum for patients with an established leakage after ileorectal anastomosis. Cook et al. [25] and Kamocka and Skipper [26] reported successful results with the use of a HSAS; however, those results came from case reports.

TD was also employed as a preventive measure that might potentially lower the incidence of $\mathrm{AL}$ and its clinical consequences [12]. Lee et al. [27] investigated the impact of using transanal tube drainage after a LAR without a defunctioning stoma on the incidence of AL. When propensity score matching was applied, patients with a transanal tube drain had a lower incidence of AL, with a reduced number of patients experiencing peritonitis; however, none of these differences reached statistical significance.

Recently, Wang et al. [28] in a systematic review and meta-analysis based on three observational studies and one randomized controlled trial (RCT) found that transanal tube drainage was associated with a significantly lower incidence of $\mathrm{AL}$ and that reoperation which may be attributed to the reduced intraluminal pressure. Ha et al. [29] in a systematic review and meta-analysis about the role of transanal tube placement after a LAR for the treatment of patients with rectal cancer in RCTs of 475 patients found no difference between both groups with and without transanal tube placement while in nonrandomized studies of 643 patients, the placement of the transanal tube was associated with a lower incidence of AL.

In our study, patients who were treated with TD had defunctioning ileostomy at the time of initial operation. The role of diversion in the prevention of $\mathrm{AL}$ is still debatable, so patients must be carefully selected. Tan et al. [30] in a meta-analysis of 4 RCTs and 21 non-RCTs reported that the absence of a stoma was associated with a higher incidence of AL, as well as a higher rate of reoperation, but the difference in the mortality rate was not statistically significant. Also, they reported morbidities from $0 \%$ to $19.8 \%$ and mortalities from $0 \%$ to $1.4 \%$ related to the subsequent stoma reversal.

In conclusion, $\mathrm{TD}$ for managing an $\mathrm{AL}$ after a resection of rectal cancer is safe, cheap, and effective. Salvaging and preserving the anastomosis will help decrease the need for reoperation and Hartmann colostomy formation. Proper patient's selection is important, and the presence of a defunctioning ileostomy decreases the need for additional reintervention.

\section{CONFLICT OF INTEREST}

No potential conflict of interest relevant to this article was reported.

\section{REFERENCES}

1. Sakr A, Emile SH, Abdallah E, Thabet W, Khafagy W. Predictive factors for small intestinal and colonic anastomotic leak: a multivariate analysis. Indian J Surg 2017;79:555-62.

2. Phitayakorn R, Delaney CP, Reynolds HL, Champagne BJ, Heriot AG, Neary P, et al. Standardized algorithms for management of anastomotic leaks and related abdominal and pelvic abscesses after colorectal surgery. World J Surg 2008;32:1147-56.

3. Daams F, Luyer M, Lange JF. Colorectal anastomotic leakage: aspects of prevention, detection and treatment. World J Gastroenterol 2013;19:2293-7.

4. Vallance A, Wexner S, Berho M, Cahill R, Coleman M, Haboubi $\mathrm{N}$, et al. A collaborative review of the current concepts and challenges of anastomotic leaks in colorectal surgery. Colorectal Dis 2017;19:O1-12.

5. Soeters PB, de Zoete JP, Dejong CH, Williams NS, Baeten CG. Colorectal surgery and anastomotic leakage. Dig Surg 2002;19: 150-5.

6. Blumetti J, Abcarian H. Management of low colorectal anastomotic leak: Preserving the anastomosis. World J Gastrointest Surg 2015;7:378-83.

7. Krarup PM, Jorgensen LN, Harling H; Danish Colorectal Cancer Group. Management of anastomotic leakage in a nationwide cohort of colonic cancer patients. J Am Coll Surg 2014;218:940-9.

8. Longo WE, Milsom JW, Lavery IC, Church JC, Oakley JR, Fazio VW. Pelvic abscess after colon and rectal surgery--what is optimal management? Dis Colon Rectum 1993;36:936-41.

9. Lindgren R, Hallböök O, Rutegård J, Sjödahl R, Matthiessen P. What is the risk for a permanent stoma after low anterior resection of the rectum for cancer? A six-year follow-up of a multicenter trial. Dis Colon Rectum 2011;54:41-7.

10. Edden $Y$, Weiss EG. Surgical considerations in anastomotic dehiscence. In: Zbar AP, Madoff RD, Wexner SD, editors. Reconstructive surgery of the rectum, anus and perineum. London: Springer; 2013. p. 511-6.

11. Thorson AG, Thompson JS. Transrectal drainage of anastomotic leaks following low colonic anastomosis. Dis Colon Rectum 1984; 27:492-4.

12. Xiao L, Zhang WB, Jiang PC, Bu XF, Yan Q, Li H, et al. Can transanal tube placement after anterior resection for rectal carcinoma reduce anastomotic leakage rate? A single-institution prospective randomized study. World J Surg 2011;35:1367-77.

13. Heald RJ. A new approach to rectal cancer. Br J Hosp Med 1979;22:277-81.

14. Rahbari NN, Weitz J, Hohenberger W, Heald RJ, Moran B, Ulrich A, et al. Definition and grading of anastomotic leakage following anterior resection of the rectum: a proposal by the International Study Group of Rectal Cancer. Surgery 2010;147:339-51.

15. Guillou PJ, Quirke P, Thorpe H, Walker J, Jayne DG, Smith AM, et al. Short-term endpoints of conventional versus laparoscopicassisted surgery in patients with colorectal cancer (MRC CLAS- 
ICC trial): multicentre, randomised controlled trial. Lancet 2005; 365:1718-26.

16. Park IJ, Choi GS, Lim KH, Kang BM, Jun SH. Laparoscopic resection of extraperitoneal rectal cancer: a comparative analysis with open resection. Surg Endosc 2009;23:1818-24.

17. Kim SH, Park IJ, Joh YG, Hahn KY. Laparoscopic resection for rectal cancer: a prospective analysis of thirty-month follow-up outcomes in 312 patients. Surg Endosc 2006;20:1197-202.

18. van der Pas MH, Haglind E, Cuesta MA, Fürst A, Lacy AM, Hop WC, et al. Laparoscopic versus open surgery for rectal cancer (COLOR II): short-term outcomes of a randomised, phase 3 trial. Lancet Oncol 2013;14:210-8.

19. Morino M, Parini U, Giraudo G, Salval M, Brachet Contul R, Garrone C. Laparoscopic total mesorectal excision: a consecutive series of 100 patients. Ann Surg 2003;237:335-42.

20. Miyajima N, Fukunaga M, Hasegawa H, Tanaka J, Okuda J, Watanabe M, et al. Results of a multicenter study of 1,057 cases of rectal cancer treated by laparoscopic surgery. Surg Endosc 2009;23: 113-8.

21. Karanjia ND, Corder AP, Holdsworth PJ, Heald RJ. Risk of peritonitis and fatal septicaemia and the need to defunction the low anastomosis. Br J Surg 1991;78:196-8.

22. Kornmann VN, Treskes N, Hoonhout LH, Bollen TL, van Ramshorst B, Boerma D. Systematic review on the value of CT scanning in the diagnosis of anastomotic leakage after colorectal sur- gery. Int J Colorectal Dis 2013;28:437-45.

23. Sirois-Giguère E, Boulanger-Gobeil C, Bouchard A, Gagné JP, Grégoire RC, Thibault C, et al. Transanal drainage to treat anastomotic leaks after low anterior resection for rectal cancer: a valuable option. Dis Colon Rectum 2013;56:586-92.

24. Brent A, Armstrong T, Nash GF, Heald RJ. Therapeutic use of the Heald Silastic Anal Stent. Colorectal Dis 2007;9:279-80.

25. Cook EJ, Moran BJ, Heald RJ, Nash GF. Pelvic collection drainage by Heald anal stent. Ann R Coll Surg Engl 2012;94:361.

26. Kamocka A, Skipper D. Drainage of a pelvic collection with the Heald Silastic Anal Stent. Colorectal Dis 2010;12:485-6.

27. Lee SY, Kim CH, Kim YJ, Kim HR. Impact of anal decompression on anastomotic leakage after low anterior resection for rectal cancer: a propensity score matching analysis. Langenbecks Arch Surg 2015;400:791-6.

28. Wang S, Zhang Z, Liu M, Li S, Jiang C. Efficacy of transanal tube placement after anterior resection for rectal cancer: a systematic review and meta-analysis. World J Surg Oncol 2016;14:92.

29. Ha GW, Kim HJ, Lee MR. Transanal tube placement for prevention of anastomotic leakage following low anterior resection for rectal cancer: a systematic review and meta-analysis. Ann Surg Treat Res 2015;89:313-8.

30. Tan WS, Tang CL, Shi L, Eu KW. Meta-analysis of defunctioning stomas in low anterior resection for rectal cancer. Br J Surg 2009; 96:462-72. 